\title{
Systematic Review on International Practices in Controlling Waterpipe Tobacco Smoking
}

\author{
Guat Hiong Tee ${ }^{1 *}$, Noran N Hairi², Fauziah Nordin', Wan Yuen $\mathrm{Choo}^{2}$, Ying Ying \\ Chan $^{1}$, Gurpreet Kaur ${ }^{3}$, Pathma Devi Veerasingam², Awang Bulgiba ${ }^{1}$
}

\begin{abstract}
Background: Waterpipe tobacco smoking has becoming popular especially among young people worldwide. Smokers are attracted by its sweeter, smoother smoke, social ambience and the misconception of reduced harm. The objective of this study was to systematically review the effects of waterpipe tobacco policies and practices in reducing its prevalence. Materials and Methods: A systematic review was conducted electronically using the PubMed, OVID, Science Direct, Proquest and Embase databases. All possible studies from 1980 to 2013 were initially screened based on titles and abstracts. The selected articles were subjected to data extraction and quality rating. Results: Three studies met the inclusion criteria and were eligible for this review. Almost all of the waterpipe tobacco products and its accessories did not comply with the regulations on health warning labelling practices as stipulated under Article 11 of WHO FCTC. In addition, the grisly new warning labels for cigarettes introduced by Food and Drug Administration did not affect hookah tobacco smoking generally. Indoor air quality in smoking lounges was found to be poor and some hookah lounges were operated without smoke shop certification. Conclusions: Our findings revealed the availability of minimal information on the practices in controlling waterpipe smoking in reducing its prevalence. The lack of comprehensive legislations or practices in controlling waterpipe smoking warrants further research and policy initiatives to curb this burgeoning global epidemic, especially among the vulnerable younger population.
\end{abstract}

Keywords: Waterpipe - Hookah - tobacco - warning labels - legislation - practices

Asian Pac J Cancer Prev, 16 (9), 3659-3665

\section{Introduction}

Waterpipe (WP) smoking is gaining its popularity not only in the Middle East region but worldwide (Cobb et al., 2010; Maziak, 2011). Other names synonymous to waterpipe include "shisha", "hookah", "goza" "narghile" and "hubble bubble" (El Hakim, 1999; Jaleel et al., 2001; Maziak et al., 2004). A waterpipe is a device used to smoke tobacco and other substances; it consists of head, body, water bowl and hose (Maziak et al., 2004). Globally, there are 100 million people who smoke WP daily (Wolfram et al., 2003). WP has been typically associated with coffee house culture whereby smokers spending between 45 and 50 minutes per session but may continue for several hours smoking with friends or families (Knishkowy and Amitai, 2005).

Waterpipe is traditionally smoked by adults; however WP smoking has been becoming a culture among young adults and adolescents (World Health Organization, 2005; Amin et al., 2010; Al-Naggar and Saghir, 2011). A recent findings from the Global Youth Tobacco Survey (GYTS) involving data from 16 countries found that the prevalence of WP smoking ranged from 6 to $34 \%$ among 13-15 years old (Warren et al., 2009). Amin et al (2010) reported that $53.9 \%$ of the current tobacco users among secondary school adolescents in Saudi Arabia smoked WP; in which $11.7 \%$ smoked WP solely. In addition, a study conducted among Jordanian university students showed a high prevalence $(42.7 \%)$ of current waterpipe smoking (Azab et al., 2010). The prevalence of ever waterpipe use had been reported to be as high as $38 \%$ among samples of British university students (Jackson and Aveyard., 2008); while current waterpipe use ranged from 7 to $20 \%$ among students in US universities (Cobb et al., 2010) and about 20\% among medical students in Malaysia (Al-Naggar and Bobryshev, 2012).

Waterpipe smoking among the general population was found to be lower than youth and college / university students (Al-Naggar et al., 2015). Morton et al reported that the current prevalence of waterpipe smoking among males in 13 countries ranged from $0.01 \%$ in Philippines to $13.0 \%$ in Vietnam (Morton et al., 2014). Similarly, a low prevalence of waterpipe smoking was found among Malaysian adults at $0.6 \%$ (Institute for Public Health,

${ }^{1}$ Institute for Public Health, Ministry of Health Malaysia, ${ }^{2}$ Julius Centre University of Malaya, Department of Social and Preventive Medicine, Faculty of Medicine, University of Malaya, ${ }^{3}$ National Institutes of Health Secretariat, Ministry of Health, Malaysia *For correspondence: helentee.gh@moh.gov.my 
2012).

The popularity of the WP smoking is by and large due to the misconception that it is less dangerous than cigarette smoking (Alvur et al., 2014) and or other forms of smoking (Amin et al., 2010; Dar-Odeh et al., 2010 ; Maziak, 2011). The popularity of WP smoking is further fuelled by the introduction of flavoured tobacco or maassel (Cinar and Cakmak, 2014), the mushrooming of shisha bars, cafes and restaurants, as well as the aggressive marketing of shisha, shisha accessories and maassel (Cobb et al., 2010; Maziak, 2010).

A recent systematic review found that waterpipe tobacco smoking was significantly associated with various diseases, such as lung cancer, respiratory illnesses, periodontal diseases and low birth weight (Akl et al., 2010)

The tobacco epidemic which is predicted to kill more than 8 million people annually by the year 2030 from tobacco-related causes receives much attention around the world (Mathers and Loncar, 2006). In contrast, WP smoking which may "represent the second global tobacco epidemic since the cigarette" (Maziak, 2011) has failed to have policies and regulations to address this impending epidemic. The objective of this systematic review was to determine the effects of waterpipe tobacco policies and practices in reducing its prevalence.

\section{Materials and Methods}

\section{Protocol and registration}

This systematic review was conducted in accordance with the Cochrane methodology and reported following the Preferred Reporting Items for Systematic Reviews and Meta-Analyses (PRISMA) guideline (Moher et al., 2009). No protocol for this review has been published. However, a protocol was developed during the planning process.

\section{Eligibility criteria}

For this review, waterpipe tobacco smoking refers to tobacco use methods in which smoke passes through water. Studies were included in this review if they reported

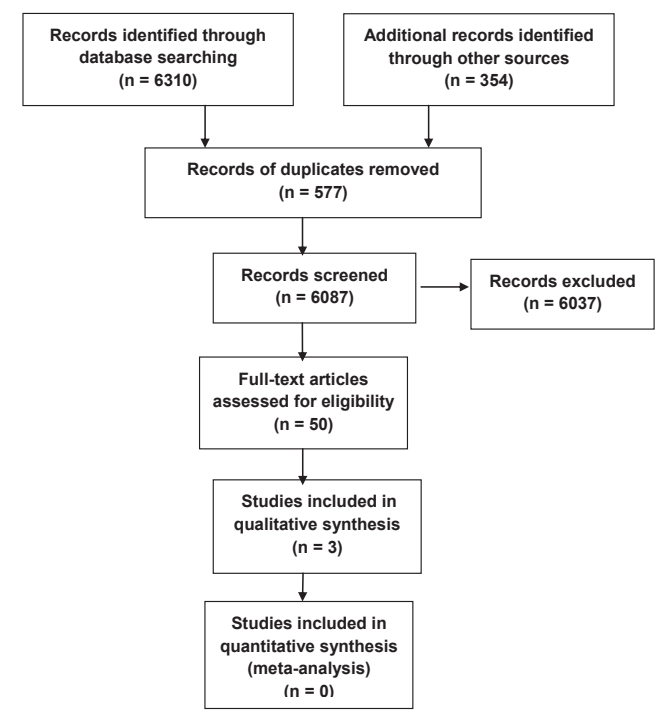

Figure 1. Flow diagram of selection strategy of included studies a change in the prevalence of waterpipe tobacco smoking when instituting the practices or policies for waterpipe smoking. Studies that only describe the policies and practices for waterpipe smoking were excluded from this review.

\section{Information sources and search strategy}

Three search strategies were used to retrieve relevant articles for this review. The English language literature was systematically searched using the following databases; PubMed, OVID, Science Direct, Proquest and Embase. Searches were carried out for studies published from 1980 to 2013. The Cochrane Library and Cochrane Database of Systematic Reviews were undertaken using the same strategy; however no new articles were found. We also undertook a hand search of journals to identify articles missed by our search. Lastly, reference lists of all selected articles were reviewed to identify other relevant papers. The review team obtained a full-text or abstract containing sufficient details to determine the eligibility of all potentially relevant studies. The databases were searched using controlled terms (e.g. Medical Subject Headings in Medline) and free text words. These words were customized to the different databases. The following search was used most frequently: "Waterpipe or waterpipe tobacco smoking" OR "shisha" or "hookah" or "hooka" or "hukka" or "Narghile" or "Hubble-bubble" or "argileh" or "goza" or "boory" AND "tobacco control" or "legislature" or "international practices" or "practices" or "controlling" or health warnings" OR "pictorial health warnings" or "text health warnings" or "textual health warnings" or "clean indoor air legislation" or "legislation".

\section{Study selection}

The initial search through database resulted in 6310 titles (Figure 1). Additional search identified through other sources found 354 articles. Duplicates were removed and a total of 6087 titles were screened. Two reviewers (GHT and FN) screened all the titles to find eligible studies. Both reviewers were overly inclusive at this stage and if in doubt, a third reviewer was called to resolve the disagreement. We included all possible studies from 1980 to 2013. Only English language articles were selected. The most important criteria was whether these articles could describe the practices and policies in controlling shisha, hookah or waterpipe tobacco smoking in reducing its prevalence. Fifty articles were selected and the abstracts

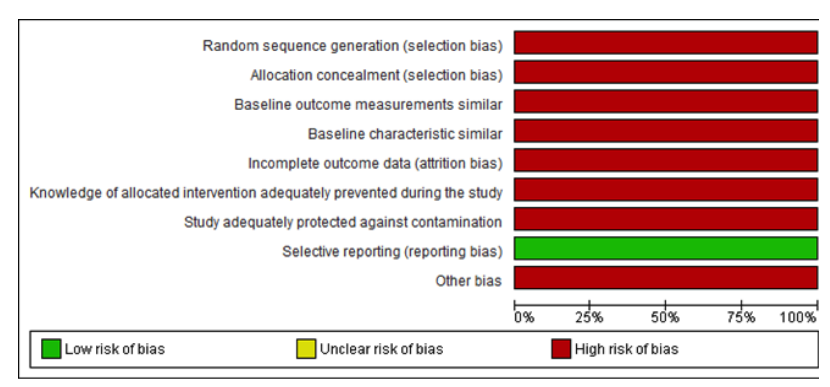

Figure 2. Risk of Bias Graph - Review Authors' Judgements about Each Risk of Bias Item Presented as Percentages across all Included Studies 
read (GHT and FN). Articles were selected when they presented a study (not a review or comment or personal opinion) on practices in controlling shisha, hookah or waterpipe tobacco smoking. Qualitative studies were excluded. Finally, five experts in the area reviewed our final study selection to identify any missing literature. Three articles met the above-mentioned criteria.

\section{Data collection process}

Two reviewers designed the data extraction form. Five reviewers independently assessed each full-text article and extracted the required data. The following items were extracted: author and year of study, country, study characteristics, sample characteristics, interventions and outcome.

\section{Risk of bias in individual studies}

The risk of bias of each eligible study was assessed by two reviewers (NNH and WYC) using the Cochrane Effective Practice and Organisation of Care Group (EPOC) tool. The results are summarised in the 'Risk of bias graph', which is an overview of judgement on each risk of bias item presented as percentages across all included studies (Figure 2). We present Figure 3 which shows the 'Risk of bias' summary for each individual risk of bias item for each included study. The datasets were compared and where there were disagreements between the investigators in the risk of bias assessment, this was resolved by discussion and consensus. Studies were assessed for the five general domains of bias; selection, performance, attrition, detection and reporting, and additional category for additional concerns pertaining to the study quality that do not fit the five domains.

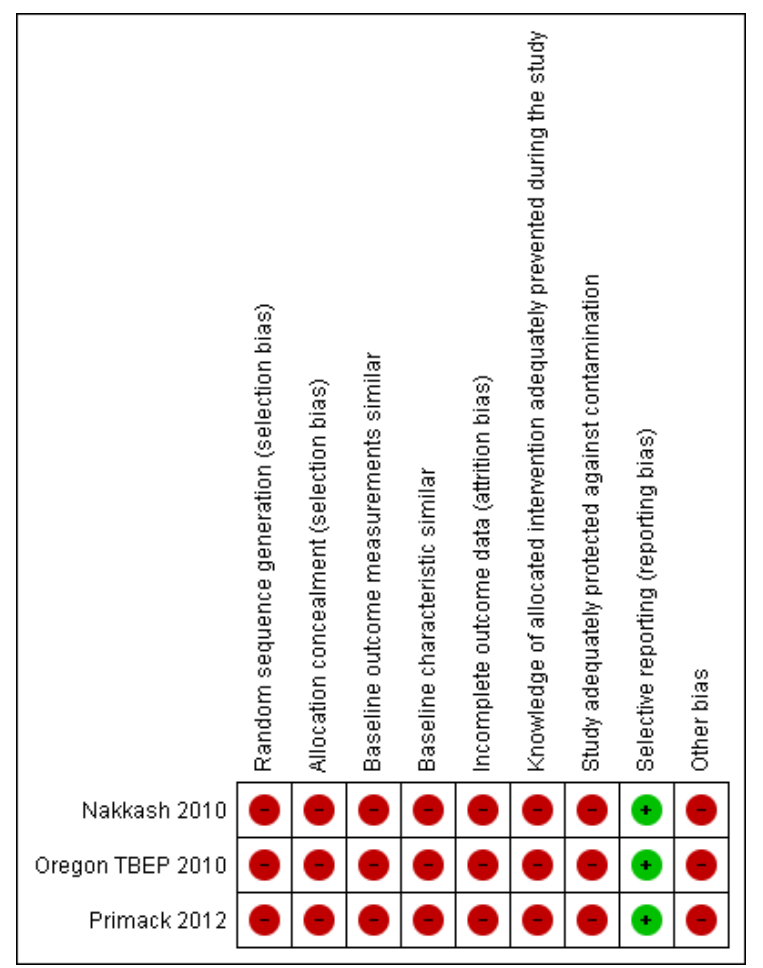

Figure 3. Risk of Bias Summary - Review Authors' Judgements About Each Risk of Bias Item for Each Included Study

\section{Results}

\section{Study selection}

This systematic review included five databases; i.e. PubMed, OVID, Science Direct, ProQuest and Embase. In addition, 23 individual searches were carried out. The literature search using specific search terms identified 6310 articles from the electronic databases and 354 articles using hand search identified through our top yield journals that meet the inclusion criteria as listed in the Appendix. Following title and abstract screening, 6037 were excluded from the selection process and 50 full-text articles that deemed potentially relevant were obtained for detailed review (Figure 1). Of these, three studies met the inclusion criteria and were included in this review. These articles were reviewed by two independent reviewers.

\section{Study characteristics}

The main characteristics of these three included studies are presented in Table 1. The included studies only reported some form of practices but not directly addressed the practices towards waterpipe smoking. All studies meeting the inclusion criteria only provided minimal information on the practices in controlling waterpipe smoking.

\section{Risk of bias}

The results of the risk of bias assessment for the three included studies are presented in Figure 2 and Figure 3. Overall, we found the risk of bias in the included studies was high (Figure 2).

\section{Results of individual studies}

Nakkash and Khalil (2010) conducted a study on 74 waterpipe tobacco products; 39 from Lebanon and 35 from other countries (Dubai, Palestine, Syrian Arab Republic, Jordan, Bahrain, Canada, Germany, and South Africa). They found that almost all of the waterpipe tobacco products did not complied with the regulations on health warning labelling practices as stipulated under Article 11 of WHO FCTC (World Health Organization, 2003) with the exception of Germany, Palestine and South Africa. All health warning labels were textual and covered on average $3.5 \%$ of total surface area and placed only on one side of the packages with no rotation. However, the textual health warning labels from Germany, Palestine and South Africa covered up to $30 \%$ of the front and back packages of these products. In addition, $77 \%$ of the tobacco products also had erroneous qualitative descriptors; i.e. $0.0 \%$ tar and $0.5 \%$ nicotine, which were considered to be misleading under Article 11 of WHO FCTC (World Health Organization, 2003).

On 35 waterpipe related accessories; i.e. filter mouthpieces, aluminium foil and charcoal packages studied by the reviewers, only three filters had a generic health warning label on the side or back of the packs. Similarly, qualitative misleading descriptors were found to occupy on an average $17 \%$ of the total surface area of waterpipe related accessories packages (Nakkash and Khalil 2010). The authors concluded that a more thorough evaluation of health warning label practices has to be 
carried out to determine the reduction in the prevalence of waterpipe smoking.

A study using secondary data assessing tobaccorelated clean air policies which might apply to hookah tobacco smoking (HTS) in 100 most populous cities in USA was conducted by Primack et al. (2012). The authors found that only 73 cities had comprehensive anti-tobacco legislation in place on the municipal, county or state level that disallowed cigarette smoking in freestanding bars. However, 69 of these cities may allow HTS via exemption; only four cities had comprehensive clean air laws and no exemption for HTS. The study also found that grisly new warning labels for cigarettes introduced by Food and Drug Administration did not affect HTS generally.

An observational study and focus group discussion were conducted by Oregon Tobacco Prevention and education Program in 2010 to assess compliance with the Oregon's amended Indoor Clean Air Act (ICAA) among certified smoke shops, certified cigar bars and potential indoor smoking lounges (Oregon Tobacco Prevention and Education Program, 2010). The study measured compliance (exterior, interior, marketing assessment) for certified cigar bars and smoke shops as well as indoor air quality (PM 2.5) for smoking lounges and tobacco retails stores. The study found that among businesses certified for exemption from the indoor smoking ban had high compliance with ICAA except for improper signage. Indoor air quality in smoking lounges was poor and some hookah lounges were operated without smoke shop certification. The secondary objective of the study aimed to describe hookah lounges as social environment for WP users but no baseline assessment was measured prior to their study. Therefore changes in the prevalence of WP users could not be determined.

\section{Assessment of Risk of Bias}

The results of the risk of bias assessment for the three included studies are presented in Figure 2 and Figure 3. Overall, we found the risk of bias in the included studies was high (Figure 2).

Table 1. Characteristics of Included Studies

\begin{tabular}{|c|c|c|c|c|c|}
\hline Author (year) & Country & Study characteristics & Sample characteristics & Interventions & Outcomes \\
\hline Nakkash (2010) & $\begin{array}{l}\text { Lebonan and other } \\
\text { countries (Dubai, } \\
\text { Palestine, Syria, } \\
\text { Jordan, Bahrain, } \\
\text { Canada, Germany, } \\
\text { South Africa) }\end{array}$ & $\begin{array}{l}\text { "Objective: An } \\
\text { evaluation of current } \\
\text { health warning } \\
\text { labelling practices } \\
\text { of waterpipe tobacco } \\
\text { products and related } \\
\text { accessories } \\
\text { Method: All water- } \\
\text { pipe tobacco brands } \\
\text { in Lebanon and a } \\
\text { convenience sample } \\
\text { from other coun- } \\
\text { tries" }\end{array}$ & $\begin{array}{l}\text { "Tobacco products: } \\
74 \text { samples ( } 39 \text { from } \\
\text { Lebanon and } 35 \text { from } \\
\text { other countries) } \\
\text { Waterpipe-related } \\
\text { accessories: } \\
\text { - } 35 \text { samples ( } 8 \text { types } \\
\text { of filter tips, } 4 \text { types of } \\
\text { mouthpieces, } 7 \text { types } \\
\text { of aluminium foil and } \\
16 \text { types of charcoal)" }\end{array}$ & $\begin{array}{l}\text { Health warning } \\
\text { labelling } \\
\text { practices of } \\
\text { waterpipe } \\
\text { tobacco products } \\
\text { and related } \\
\text { accessories }\end{array}$ & $\begin{array}{l}\text { "1. Lack of } \\
\text { appropriate health } \\
\text { warning labels on } \\
\text { waterpipe tobacco } \\
\text { products and } \\
\text { accessories } \\
\text { 2. Misleading } \\
\text { qualitative } \\
\text { descriptors } \\
\text { 3. Misreporting } \\
\text { of tar and nicotine } \\
\text { labels" }\end{array}$ \\
\hline $\begin{array}{l}\text { Oregon } \\
\text { Tobacco } \\
\text { Prevention } \\
\text { and Education } \\
\text { Program (2010) }\end{array}$ & United States & $\begin{array}{l}\text { "Objective: To assess } \\
\text { compliance with the } \\
\text { Oregon's amended } \\
\text { Indoor Clean Air } \\
\text { Act (ICAA) among } \\
\text { certified smoke } \\
\text { shops, certified cigar } \\
\text { bars and potential } \\
\text { indoor smoking } \\
\text { lounges } \\
\text { Method: Data } \\
\text { collection based } \\
\text { on observation and } \\
\text { measurement: } \\
\text { 1. Compliance } \\
\text { (exterior, interior, } \\
\text { marketing } \\
\text { assessment) for } \\
\text { certified cigar bars } \\
\text { and smoke shops } \\
\text { 2. Indoor air quality } \\
\text { (PM2.5) for smoking } \\
\text { lounges and tobacco } \\
\text { retails stores" }\end{array}$ & $\begin{array}{l}\mathrm{N}=38 \text { including } \\
\text { certified smoke shops } \\
(\mathrm{n}=15) \text { and certified } \\
\text { cigar bars }(\mathrm{n}=8), \text { Non- } \\
\text { certified, potential } \\
\text { smoking lounges ( } \mathrm{n} \\
=15)\end{array}$ & $\begin{array}{l}\text { "Compliance of } \\
\text { ICAA exemption } \\
\text { requirements: } \\
\text { 1. Cigar bars ( } 7 \\
\text { items) } \\
\text { 2. Smoke shops } \\
\text { (5 items)" }\end{array}$ & $\begin{array}{l}\text { "1. Compliance } \\
\text { rates with the } \\
\text { ICAA varied } \\
\text { among businesses } \\
2 \text {. Indoor } \\
\text { air quality } \\
\text { varied among } \\
\text { businesses." }\end{array}$ \\
\hline
\end{tabular}




\begin{tabular}{|c|c|c|c|c|c|}
\hline Primack (2012) & United States & $\begin{array}{l}\text { "Objectives: To } \\
\text { assess how a } \\
\text { representative } \\
\text { sample of US } \\
\text { tobacco control } \\
\text { policies may apply } \\
\text { to HTS (hookah } \\
\text { tobacco smoking) } \\
\text { and to determine } \\
\text { associations between } \\
\text { community-level } \\
\text { sociodemographic } \\
\text { factors and HTS } \\
\text { policy status } \\
\\
\text { Method: Tobacco- } \\
\text { related clean air } \\
\text { policies was assessed } \\
\text { for each of the } 100 \\
\text { most populous US } \\
\text { cities (according to } \\
\text { the } 2010 \text { census) } \\
\text { at the municipal, } \\
\text { county and state } \\
\text { level according } \\
\text { to business } \\
\text { establishments: } \\
\text { i. Smoking legal } \\
\text { ii. HTS exempt } \\
\text { iii. Tobacco Retail } \\
\text { Establishment (TRE) } \\
\text { exempt } \\
\text { iv. Strict" }\end{array}$ & $\begin{array}{l}\text { "n= } 100 \text { cities } \\
\text { mean (SD) of socio- } \\
\text { demographic variables } \\
\text { - Population, 598,499 } \\
(921,037) \\
\text { - Population density, } \\
\text { persons per square } \\
\text { mile 4,603 (3,977) } \\
\text { - Median income, US } \\
\text { \$/year } \\
\text { 48,196 (12,710) } \\
\text { - Median age, years } \\
33(3) \\
\text { - Race \& ethnicity } \\
\text { - White 60 (16) } \\
\text { - Black 21 }(18) \\
\text { - Asian 7 }(9) \\
\text { - Hispanic 23 }(21) \\
\text { - Geographic Region } \\
\text { - Midwest }(\mathrm{n}=17) \\
\text { - Northeast }(\mathrm{n}=8) \\
\text { - South }(\mathrm{n}=38) \\
\text { - West }(\mathrm{n}=37)\end{array}$ & $\begin{array}{l}\text { Tobacco-related } \\
\text { clean air policies }\end{array}$ & $\begin{array}{l}\text { "1. Percentages of } \\
\text { cities by clean air } \\
\text { policies type } \\
2 \text {. Associations } \\
\text { between } \\
\text { community-level } \\
\text { socio-demographic } \\
\text { variables and the } \\
\text { policy outcome } \\
\text { variable" }\end{array}$ \\
\hline
\end{tabular}

\section{Discussion}

We performed a comprehensive systematic review of the literature to address the practices in controlling waterpipe smoking; and three articles fulfill the search terms. Two of the studies were primary studies (Nakkash and Khalil, 2010; Primack et al., 2012) and the third one utilising secondary data and focus group discussion (Oregon Tobacco Prevention and Education Program, 2010). However, there was insufficient information on the practices in controlling waterpipe smoking to reduce its prevalence from all the three included studies. More well-designed and rigorous studies with low risk of bias are required to draw any conclusion on the impact of controlling waterpipe smoking in future.

Many policies related to tobacco control have been enforced in most of the countries; such as smoke-free environment, restrictions on sales of tobacco products to minors, ban on the advertising and increasing taxes of tobacco products (Ali Al-Bakri, 2015). However, there is no policy specifically addressing the use of waterpipe smoking despite World Health Organization's declaration of waterpipe smoking as a new public health problem (World Health Organization, 2005). In addition, WHO FCTC Articles 10 and 11 (World Health Organization, 2003) also recommend countries to regulate waterpipe smoking. Presently, waterpipe smoking is not consistently regulated or in compliance with regulations. The sales of waterpipe tobacco and its accessories as well as its content and packaging are not standardized.
In fact, many waterpipe bars are exempted from clean indoor air legislation where they are operating in the disguise of tobacco retail businesses (Noonan D, 2010). Additionally, waterpipe use is exempted from minor's access law (Maziak, 2011). Since waterpipe tobacco is not currently regulated; including by US Food and Drug Administration and the Canadian Food Inspection Agency, therefore the packaging descriptions and content are also unregulated. Other accessories, sold on the market are similarly not standardized (United States Food and Drug Administration, 2009).

Responding to the increasing prevalence of waterpipe smoking especially among youth, WHO Study Group on Tobacco Product Regulation (TobReg) makes eight recommendations to regulate waterpipe smoking including strong health warnings, prohibition of smoking in public places and misleading labelling such as "contains $0 \mathrm{mg}$ tar" consistent with tobacco control regulations on cigarettes in 2005. This advisory note concluded that "using a waterpipe to smoke tobacco poses a serious potential health hazard to smokers and others exposed to the smoke emitted" (World Health Organization, 2005).

The introduction of flavoured and sweetened tobacco in waterpipe smoking has gained popularity rapidly over the years especially among the younger population worldwide (Warren et al., 2009; Amin et al., 2010; Maziak, 2010; Al-Naggar and Saghir, 2011). Waterpipe smoking appeals to the youth and young adults as it is considered as a social activity; the waterpipe smoking lounges served as a place for them to do something new and fun with 
friends without being stigmatised or shamed as compared to cigarette smoking (Oregon Tobacco Prevention and Education Program, 2010).

We performed this systematic review using an inclusive and comprehensive search strategy; using an independent selection and data extraction processes. We also followed PRISMA reporting guidelines (Moher et al., 2009) and assess the risk of bias of individual studies using the EPOC assessment criteria. We judged all three studies to have high risk of bias from four domains that includes selection, performance, attrition, detection bias. Several limitations of this study warrant consideration; firstly; the methodology used to assess the practices in controlling WP smoking was different for all three included studies. Only one study evaluated the health warning labelling practices on WP tobacco products and its accessories (Nakkash and Khalil, 2010). The other two studies assessed the compliance towards the Tobacco Control Policies and Indoor Clean Air Act in relation to WP smoking (Primack et al., 2012; Oregon Tobacco Prevention and Education Program, 2010). Due to the inconsistency in the methodologies and data collected from the studies, it was impossible to draw any conclusion on the practices in controlling WP smoking. Secondly, there was lack of outcome measurement in all the three included studies.

Despite various limitations, this systematic review highlighted the lack of comprehensive legislations or practices in controlling waterpipe smoking, whereby they are not currently regulated as cigarettes. Due to the lack of clear regulation and legislation on WP, it is generally perceived that WP is not addictive and one can stop WP smoking as and when is desired. There is misconception that waterpipe smoking is safer or less dangerous compared to cigarette smoking, even though numerous research has proven otherwise (Akl et al; 2010; Cobb et al., 2010; Dar-odeh et al., 2010; Raad et al., 2011; Morton et al., 2013). The majority of the young population as well as their parents are not aware of the danger of WP smoking; some assumed to smoke dried fruits or herbs. Furthemore, smoking waterpipe for young people may initiate addiction and as the gateway to cigarette smoking later in life (Primack et al., 2006; Dar-odeh et al., 2010; Jensen et al., 2010; Fielder et al., 2013). Therefore, it is imperative that more stringent legislations be drafted in controlling waterpipe smoking and ensures the laws are being appropriately enforced. Our findings may be valuable to researches, public health practitioners, health policy officials, and advocacy group to carry out further research in ascertaining appropriate policies, legislations and laws to curb this burgeoning global epidemic especially among the younger population. Failure to curb this global public health problem may lead to an increase in preventable smoking-related morbidity and mortality in years to come.

\section{Acknowledgements}

We would like to thank the Director General of Health, Ministry of Health Malaysia for his kind permission to publish this paper. NNH's work on this study was supported by the University of Malaya Grand Challenge PEACE grant (GC001A-14HTM).

\section{References}

Akl EA, Gaddam S, Gunukula SK, et al (2010). The effects of waterpipe tobacco smoking on health outcomes: a systematic review. Int J. Epidemiol, 39, 834-857.

Ali Al-Bakri MJ, Pascale Salameh, Mustafa al'Absi, Saba Kassim (2015). Opportunistic insights into occupational health hazards associated with waterpipe tobacco smoking premises in the United Kingdom. Asian Pac J Cancer Prev, 16, $621-6$.

Al-Naggar RA, Bobryshev YV, Anil S (2015). Pattern of shisha and cigarette smoking in the general population in Malaysia. Asian Pac J Cancer Prev, 15, 10841-6.

Al-Naggar RA, Bobryshev YV (2012). Shisha smoking and associated factors among medical students in Malaysia. Asian Pac J Cancer Prev, 13, 5627-32.

Al-Naggar RA, Saghir FSA (2011). Water pipe (shisha) smoking and associated factors among Malaysian university students. Asian Pac J Cancer Prev, 12, 3041-7.

Alvur MT, Cinar N, Akduran F, et al (2014). Fallacies about water pipe use in Turkish university students - what might be the consequences? Asian Pac J Cancer Prev, 15, 1977-80.

Amin TT, Amr MAM, Zaza BO, et al (2010). Harm perception, attitudes and predictors of waterpipe (shisha) smoking among secondary school adolescents in Al-Hassa, Saudi Arabia. Asian Pac J Cancer Prev, 11, 293-301.

Azab M, Khabour OF, Alkaraki AK, et al (2010). Water pipe tobacco smoking among university students in Jordan. Nicotine Tob Res, 12, 606-12.

Cinar N, Cakmak V (2014). Is waterpipe smoking becoming increasingly widespread among the youth? Asian Pac J Cancer Prev, 15, 8005-6.

Cobb C, Ward KD, Maziak W, et al, (2010). Waterpipe tobacco smoking: an emerging health crisis in the United States. Am $J$ Health Behav, 34, 275-85.

Cobb CO, Shihadeh A, Weaver MF, et al (2010). Waterpipe tobacco smoking and cigarette smoking: a direct comparison of toxicant exposure and subjective effects. Nicotine Tob Res, 13, 78-87.

Dar-Odeh NS, Bakri FG, Al-Omiri MK, et al (2010). Narghile (Waterpipe) smoking among university students: prevalence, pattern and beliefs. Harm Reduct J, 7, 10.

El-Hakim IE, Uthman MAE (1999). Squamous cell carcinoma and keratoacanthoma of the lower lip associated with "Goza" and "Shisha" smoking. Int J Dermatol, 38, 108-10.

Fielder RL, Carey KB, Carey MP(2013). Hookah, cigarette, and marijuana use: A prospective study of smoking behaviors among first-year college women. Addict Behav, 38, 2729-35.

Institute for Public Health (IPH) (2012). Report of the Global Adult Tobacco Survey (GATS) Malaysia, 2011. Ministry of Health Malaysia, 2012.

Jackson D, Aveyard P (2008). Waterpipe smoking in students: prevalence, risk factors, symptoms of addiction, and smoke intake. Evidence from one British university. BMC Public Health, 8, 174.

Jaleel MA, Noreen R, Hameed A, et al (2001). An epidemiological study of smoking at Abbottabad. J Ayub Med Coll Abbottabad, 13, 33-5.

Jensen PD, Cortes R, Engholm G, et al (2010). Waterpipe use predicts progression to regular cigarette smoking among Danish youth. Subst Use Misuse, 45, 1245-61.

Knishkowy B, Amitai Y (2005). Water-pipe (narghile) smoking: an emerging health risk behavior. Pediatrics, 116, 113-9.

Mathers CD, Loncar D (2006). Projections of global mortality 
andburden of disease from 2002 to 2030. PLoS Medicine, 3, 442 .

Maziak W, Fouad M F, Hammal F, et al (2004). Prevalence and characteristics of narghile smoking among university students in Syria. Int J Tub and Lung Dis, 8, 882-9.

Maziak W, Ward, KD, Soweid RAA, et al (2004). Tobacco smoking using a waterpipe: a re-emerging strain in a global epidemic. Tob Control, 13, 327-33.

Maziak W (2010). The waterpipe - A global epidemic or a passing fad. Intl J Epidemiol, 39, 857-859

Maziak W (2011). The global epidemic of waterpipe smoking. Addict Behav, 36, 1-5.

Moher D, Liberati A, Tetzlaff J, et al (2009). Preferred Reporting Items for Systematic Reviews and Meta-Analyses: the PRISMA statement. BMJ, 339, 2535.

Morton J, Song Y, Fouad H, et al (2014). Cross-country comparison of waterpipe use: nationally representative data from 13 middle-income countries from the Global Adult Tobacco Survey (GATS). Tob Control, 23, 419-27.

Nakkash R, Khalil J (2010). Health warning labelling practices on narghile (shisha, hookah) waterpipe tobacco products and related accessories. Tob Control, 19, 235-9.

Noonan D (2010). Exemptions for hookah bars in clean indoor air legislation: A public health concern. Public Health Nursing, 27, 49-53.

Oregon Tobacco Prevention and Education Program (2010). Indoor Clean Air Compliance Study.

Primack BA, Aronson JD, Agarwal AA (2006). An old custom: a new threat to tobacco control (Letter). Am J Public Health, 96, 1339.

Primack BA, Hopkins M, Halett C, et al (2012). US Health policy related to hookah tobacco smoking. Am J Pub Health, 102, 47-51.

Raad D, Gaddam S, Schunemann HJ, et al (2011). Effects of water-pipe smoking on lung function: A systematic review and meta-analysis. Chest, 139, 764-74.

United States Food and Drug Administration (2009). Tobacco Products. Available: http://www.fda.gov/TobaccoProducts/ default.htm. Accessed 2014 Jun 10.

Warren CW, Lea V, Lee J, et al (2009). Change in tobacco use among 13-15 year olds between 1999 and 2008: findings from the Global Youth Tobacco Survey. Global Health Promot, 16, 38-90.

World Health Organization (2003). Conference of the Parties to the WHO FCTC. WHO Frame work Convention on Tobacco Control, Geneva, Switzerland. World Health Organisation. Available: http://www.who.int/fctc. Accessed 2014 Jun 10.

World Health Organization Study Group on Tobacco Product Regulation (TobReg) (2005). Advisory Note: Waterpipe Tobacco Smoking: Health Effects, Research Needs and Recommended Actions by Regulators. Geneva, Switzerland: World Health Organization, 1-20.

Wolfram RM, Chehne F, Oguogho A, et al. (2003). Narghile (waterpipe) smoking influences platelet function and (iso-) eicosanoids. Life Science, 74, 47-53. 